\section{Un aporte a la cronología de las cartas paulinas*}

Eduardo de la Serna ${ }^{a}$

Pontificia Facultad Teológica, Teresianum, Italia http:/ / orcid.org/0000-0002-6459-5678

RECIBIDO: 04-12-18. APROBADO: 18-03-19

Resumen: Las cartas de Pablo no son fáciles de ordenar cronológicamente y las opiniones al respecto son dispares. Tras presentar diferentes posturas, este artículo se inclina por fechar la Carta a los Gálatas como posterior a la primera de Corintios. Un ejemplo que alude a la mujer y al varón "en Cristo" (Gálatas), o su ausencia (1Corintios), ilustra la importancia del tema.

Palabras clave: Cronología paulina; Gálatas; 1Corintios; varón-mujer.

\section{Contribution to the Chronology of the Pauline Letters}

Aвstract: It is not easy to order Paul's letters chronologically, and there are different opinions about the topic. The present article, after presenting several viewpoints, favors dating the Letter to the Galatians after the First to Corinthians. An example that refers to woman and man "in Christ" (Galatians), or their absence (1Corinthians), illustrates the importance of this subject matter.

KeY words: Pauline Chronology; Galatians; 1Corinthians; Man-woman.

\section{Cómo CITAR:}

De la Serna, Eduardo. "Un aporte a la cronología de las cartas paulinas". Theologica Xaveriana (2020): 1-22. https://doi. org/10.11144/javeriana.tx70.accp

*Artículo de investigación

${ }^{a}$ Autor de correspondencia. Correo electrónico: edelaserna96@gmail.com 


\section{Introducción}

La cronología de las cartas paulinas está lejos de ser unánimemente aceptada. Esto es algo que se complica aún más si reconocemos como originales del Apóstol alguna, algunas o todas las cartas llamadas habitualmente deuteropaulinas o antilogumena, y acaso también (alguna de) las denominadas "pastorales".

En general hay consenso (no unánime) en reconocer 1Tesalonicenses como la primera carta, pero aquí termina la casi-unanimidad. A modo de simple ejemplo notemos que, si bien era habitual ver la Carta a los Romanos como la última y una suerte de "testamento" de Pablo, actualmente no hay acuerdo sobre la fecha que debiera atribuirse a Filipenses o a Gálatas, a las que algunos consideran posteriores a aquella. François Vouga, por ejemplo, sostiene que Gálatas fue escrita por Pablo después de la Carta a los Romanos, al tomar-desde una perspectiva más conflictiva- elementos de esta carta ${ }^{1}$. Otros autores proponen que Filipenses fue escrita desde Cesarea o desde Roma ${ }^{2}$, por lo que (también) esta sería posterior a de Romanos, escrita desde Corinto.

Sin duda no se trata de un lapso amplio (por ejemplo, es habitual fechar 1 Tesalonicenses cerca del año 51 y Romanos en torno del 57). Sin embargo, la vida de las comunidades, los conflictos, las vicisitudes, preguntas o crisis y las peripecias del mismo Pablo provocan, en más de una ocasión, cambios, evolución o procesos en su pensamiento y su comunicación con las comunidades.

\section{Un ejemplo: varón y mujer "en Cristo"}

Veamos a modo de ejemplo una misma idea en dos cartas diferentes:

- "Ya no hay judío ni griego; no hay esclavo ni libre; no hay varón y mujer, pues todos ustedes son uno en Cristo Jesús”. (Ga 3,28)

\footnotetext{
${ }^{1}$ Vouga, Yo Pablo. Si bien -como diremos- en la Introducción al Nuevo Testamento (2004) propone una fecha anterior, en esta obra narrativa -presentada como un diario de Pablo- lo imagina escribiendo a los Gálatas después de la Carta a los Romanos.

${ }^{2}$ Thiselton, The Living Paul. An Introduction to the Apostle's Life and Thought, ix. Es interesante una rápida mirada por los comentarios a Filipenses. En general, ninguno lo afirma con certeza, aunque se inclinan por Éfeso: Joachim Gnilka, Des Philipperbrief (Freiburg-Basel-Wien: Herder, 1968), 24; Rinaldo Fabris, Lettera ai Filippewsi - Lettera a Filemone (Bologna: Edizioni Dehoniane Bologna, 2000), 34; John Reuman, Philippians. A New Trasnlation with Introduction and Commentary (New Haven-London: Yale University Press, 2008), 14; por Cesarea: Ben Witherington III, Paul's Letter to thePhilippians. A Sociorhetorical Commentary (Grand Rapids, MI-Cambridge, U.K.: W. B. Eermans Publishing Co., 2011, 11; o Roma: Peter T. O’Brien, New International Greek Testament Commentary (Grand Rapids, MI: W. B. Eermans Publishing Co., 1991), 25; Gordon D. Fee, Paul's Letter to the Philippians (Grand Rapids, MI: W. B. Eermans Publishing Co., 1995), 37; Camille Focant, La Carta a los Filipenses (Salamanca: Sígueme, 2016), 39.
} 
- $\quad$ "Porque en un solo Espíritu en un cuerpo todos hemos sido bautizados, ya judíos, ya griegos, ya esclavos, ya libres. Y todos hemos bebido de un Espíritu”. $(1$ Co 12,13$)$

La semejanza de ambos con el texto de Col 3,11 invita a pensar que nuclearmente nos encontramos ante un texto bautismal que Pablo ha recibido; pero sea lo que fuere, una pregunta importante es: ¿Añade Pablo el par varón-mujer en Gálatas o, por el contrario, lo omite en 1Corintios?

Sin duda saber qué carta es anterior permitirá conocer la respuesta y vislumbrar los motivos del añadido o de la exclusión. El significativo tema del lugar de la mujer en las cartas de Pablo encuentra aquí un elemento interesante a tener en cuenta. El Apóstol empieza a limitar el lugar de las mujeres en sus comunidades y por eso omite varón-mujer (si 1Corintios fuera posterior a Gálatas), o quiere resaltar el lugar de igualdad de las mujeres en sus comunidades, y por eso añade el par varón-mujer (si Gálatas fuera posterior a 1Corintios). No nos detendremos aquí en el tema de la mujer (y el varón) en las comunidades paulinas pero, sin duda, la cronología aporta un elemento para una mejor comprensión.

Es interesante, aunque escapa a nuestro tema, que -como se ve- Pablo no abandona "las categorías judío y pagano", y como señala Pamela Eisenbaum, sin duda, en la diversidad paulina, los pueblos diferentes están incluidos ${ }^{3}$.

Ya hemos anotado, en otro trabajo, que la forma redaccional del texto de Gálatas es diferente al introducirse el par varón-mujer. Mientras que en los primeros pares, judío-griego y esclavo-libre, la forma es ouk ení... oudè (ni... ni...) al referirse a varón-mujer dice ouk ení... kaì (ni... y.... $)^{4}$. Ya no se trata, entonces, de las dos puntas de un grupo étnico-religioso o social sino del par de género en su conjunto.

La fórmula ársen kai thêly es frecuente en la Biblia en el sentido de "macho y hembra" (Gn 6,19.20; 7,2.3.9.16; Lv 3,1.6) aunque también se aplica a la especie humana (Gn 1,27; Ex 1,16.22; Lv 12,7; 15,33; 27,5.6.7; véase 2 M 7,21; Mc 10,6; Mt 19,4; Rm 1,27). El patrón, habitualmente sacerdotal, es propio de LXX y quizás por eso es añadido por Pablo (las otras dos veces que se encuentra en el Nuevo Testamento corresponde a la cita de Gn 1,27); pero esto no responde al planteamiento, pues al tratarse probablemente de un texto prepaulino, Pablo podría haberlo añadido al escribir Gálatas y luego no añadirlo (o excluirlo) en Corintios.

Nosotros proponemos que 1Corintios es anterior a Gálatas y, en 12,13, Pablo repite (con las adaptaciones del caso necesarias en la carta, por ejemplo, la referencia al

\footnotetext{
${ }^{3}$ Eisenbaum, Pablo no fue cristiano. El mensaje original de un apóstol mal entendido, 397.

${ }^{4}$ De la Serna, "El lugar de la mujer en los escritos de Pablo", 381-382.
} 
"espíritu" ante la pregunta por "los espirituales", 1Co 12,1) el texto bautismal que ha recibido. En esta carta, en más de una ocasión, Pablo enfrenta el tema de la mujer en la asamblea $(11,2-16$; como hemos dicho no consideramos $14,33 \mathrm{~b}-36$ pertenecientes a la carta original sino un ańadido posterior $)^{5}$ y la sitúa en un mismo nivel con el varón. No solo señala la compostura y actitud del varón y de la mujer en la asamblea, sino que, coherentemente con lo que presentó en 1Co 7, dice algo de uno y luego dice lo mismo de la otra (hermano-hermana) en un nivel de igualdad.

El varón y la mujer -para Pablo en 1Corintios- son presentados en un modo de equivalencia. La unidad en el cuerpo es el tema central de la unidad. Los extremos judío-griego y esclavo-libre se integran (se in-corporan) en la comunidad eclesial. Cuando un tiempo después (no necesariamente prolongado), Pablo escribe a los Gálatas, el acento es diferente en una comunidad que está dividida y donde algunos pretenden excluir o rechazar a otros: los judeo-"cristianos" no reconocen a los paganos si estos no aceptan previamente incorporarse a Israel mediante el rito de la circuncisión.

En este sentido, la primera diferencia radica en que para Pablo "ya no hay": la diferencia de 1Corintios consiste en que ambos elementos "sí existen" integrados en el cuerpo; en esta carta, donde quiere destacar los "diferentes" carismas -1Co 12-, cada uno debe ser reconocido y valorado por los demás ("hay"); en Gálatas, donde algunos quieren reconocer a uno y negar al otro -judío y no griego- Pablo presenta un criterio de unidad que anula las diferencias ("no hay").

Hemos propuesto ${ }^{6}$ que el bautismo -que nos hace hermanos y hermanas- disuelve esas diferencias provocando que "ya no haya": judíos y paganos son hermanos, y como se revela en la colecta, Onésimo ya no es esclavo sino hermano de Filemón. El planteo de igualdad señalado en 1Corintios remite, por otro lado, a ese mismo tema ya presentado en Gn 1,27: "y Dios hizo al hombre, a imagen de Dios lo hizo, varón y mujer los hizo" (la Biblia de LXX traduce por poiéô el hebreo bará).

Sin embargo, esto que aquí señalamos debería ser mostrado en la cronología que intentaremos reconocer en las cartas.

\section{Diferentes opiniones sobre la cronología de ambas cartas}

Con ciertos matices y márgenes podemos afirmar que hay más consenso en precisar la fecha de 1Corintios que la de Gálatas.

\footnotetext{
${ }^{5}$ Ibíd., 400-404.

${ }^{6}$ Ibíd., 382.
} 


\section{Corintios}

Al mirar la primera Carta de Corintios, los diferentes autores suelen fecharla de este modo: Lüdemann la ubica en el año 49 (52) 7 ; Carrez, en Pascua del 55 pone 51-52 o 54-55', mientras que Vidal divide una carta A, de otońo de 52, y una carta B (respuesta a la carta corintia) de primavera de $53^{10}$; para Schrage, fines del 51 es el terminus a quo, y se la debe ubicar pasados unos tres años, es decir, entre 51-54

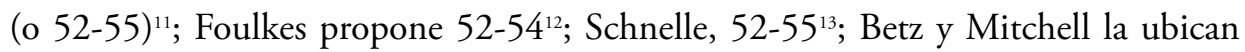
entre 53 y $55^{14}$, igual que Hays ${ }^{15}$; y Fee, en la "primavera de 53-55" ${ }^{16}$; Barrett propone principios del 54 o fines del $53^{17}$; Foulkes precisa que entre 53 y $54^{18}$; Barbaglio es partidario de 53-54, "uno o dos años después de la partida del istmo" 19 , y también Collins ("ciertamente no después del 57") 20.

Horsley afirma que Pablo deja Corinto en el 51 y escribe a los corintios unos dos años después ${ }^{21}$. Según Legasse, Pablo escribe "unos meses después de la llegada a Efeso [...], o sea, a lo largo del año 54"22. Murphy-O'Connor también afirma que en el 5423: a comienzos del 54, precisa ${ }^{24}$, y luego dice que "un día cercano, pero anterior al 2 de junio, la fecha de Pentecostés (1Co 16,8) del año 54 a. C., Pablo escribió la carta que hoy conocemos como primera Carta a los Corintios" ${ }^{25}$. Lambrecht la ubica

${ }^{7}$ Lüdemann, Paulus, der Heidenapostel. Bd. 1. Studien zur Chronologie, 273.

${ }^{8}$ Carrez, "Paul et l'église de Corinthe", 60.

${ }^{9}$ Vouga, "La primera Carta a los Corintios", 193.

${ }^{10}$ Vidal, Pablo. De Tarso a Roma, 139-142.

${ }^{11}$ Schrage, Der erste Brief an die Korinther I, 36.

${ }^{12}$ Foulkes, Problemas pastorales en Corinto. Comentario exegético-pastoral a 1Corintios, 59.

${ }^{13}$ Schnelle, Apostle Paul. His Life and Theology, 54.

${ }^{14}$ Betz y Mitchell, "Corinthians, First Epistle to the", 1140.

${ }^{15}$ Hays, First Corinthians, 5.

${ }^{16}$ Fee, The First Epistle to the Corinthians, 5.

${ }^{17}$ Barrett, La prima Lettera ai Corinti. Testo e commento, 16.

${ }^{18}$ Foulkes, "Primera Carta a los Corintios", 819.

${ }^{19}$ Barbaglio, La prima Lettera ai Corinzi. Introduzione, versione e commento, 44.

${ }^{20}$ Collins, First Corinthians, 24.

${ }^{21}$ Horsley, 1Corinthians, 29.33.

${ }^{22}$ Légasse, Pablo Apóstol. Ensayo de biografía crítica, 197.

${ }^{23}$ Murphy-O'Connor, "The First Letter to the Corinthians", 799.

${ }^{24}$ Murphy-O’Connor, Paul. A Critical Life, 252-253; 276-277.

${ }^{25}$ Murphy-O’Connor, Pablo, su historia, 262. 
en otoño de 5426, y Vielhauer, en primavera del 54, 55 o 5627; Kümmel ${ }^{28}$, Taylor ${ }^{29}$ y Lang $^{30}$ proponen la primavera del 54 o 55; y Thiselton se les asemeja: $54-55^{31}$. Brown estima 54-55 o 56-5732; para Sánchez Bosch ${ }^{33}$ es el primer trimestre del 55; Lohse la ubica a principios de ese mismo año ${ }^{34}$; Conzelmann, en la primavera, cerca de 55 $5^{35}$; Schnelle, en el año 55 $5^{36}$, y también Salvador ${ }^{37}$.

Orr y Walter ${ }^{38}$ la fechan en el 56; y Fitzmyer a "fines del 56 o más probablemente comienzos del 57"39; Guthrie, en la primavera del 5740, igual que Cambier ${ }^{41}$ y Kugelman ${ }^{42}$; Wickenhauser y Schmid ${ }^{43}$ precisan que la fecha es la Pascua de 57 . Senft considera la carta D $(1,1-4,21)$ cercana en el tiempo a 2Corintios ${ }^{44}$.

La carta se ubica, entonces, entre el 49 (y mayoritariamente el 52) y el 57; pero la variación supone diferencias en el conjunto de las cartas (hay consenso, por ejemplo, que 1 Corintios es anterior a 2Corintios y a Romanos), no en 1Corintios exclusivamente.

\section{Gálatas}

Al considerar Gálatas, las propuestas sobre su datación -como se ve- son mucho más variadas.

${ }^{26}$ Lambrecht, "1Corintios", 145.

${ }^{27}$ Vielhauer, Historia de la literatura cristiana primitiva, 158.

${ }^{28}$ Kümmel, Introduction to the New Testament, 279.

${ }^{29}$ Taylor, 1Corinthians. An Exegetical and Theological Exposition of Holy Scripture, 21.

${ }^{30}$ Lang, Die Briefe an die Korinther, 4.

${ }^{31}$ Thiselton, The First Epistle to the Corinthians, 29-32.

${ }^{32}$ Brown, An Introduction to the New Testament, 512.

33 Sánchez Bosch, Escritos paulinos, 198.

${ }^{34}$ Lohse, Introducción al Nuevo Testamento, 73.

${ }^{35}$ Conzelmann, First Corinthians: A Commentary on the First Epistle to the Corinthians 4, Nota 31: "La relación cronológica entre 1Corintios y Gálatas no puede establecerse con seguridad”.

${ }^{36}$ Schnelle, Einleitung in das Neue Testament, 75.

${ }^{37}$ Salvador-García, "Primera Carta a los Corintios", 451.

${ }^{38}$ Orr y Walter (traducción, introducción y notas), ICorinthians, 120.

${ }^{39}$ Fitzmyer, First Corinthians, 48.

${ }^{40}$ Guthrie, New Testament Introduction, 329.

${ }^{41}$ Cambier, "La primera Epístola a los Corintios", 392.

${ }^{42}$ Kugelman, "Primera Carta a los Corintios" IV, 11.

${ }^{43}$ Wickenhauser y Schmid, Introducción al Nuevo Testamento, 651.

${ }^{4}$ Senft, La première Épitre de Saint Paul aux Corinthiens, 18. 
Influye, es sabido, si se trata de comunidades gálatas del norte o del sur: para Cerfaux, "quizá preceda también a la primera a los Corintios" ${ }^{45}$; Guthrie la ubica "antes del 'Concilio", en 49-50. ${ }^{46}$ De acuerdo con el criterio de la colecta, Martyn propone una fecha temprana (1Co 16,1 aludiría a una segunda carta perdida ${ }^{47}$ ); Lüdemann ${ }^{48}$ y Perrot ${ }^{49}$ proponen el verano de 50 (53). Para de Boer fue escrita poco después de 1Tesalonicenses (en 51) ${ }^{50}$. Martin afirma: "En el tiempo de su escrito a 1Corintios, Pablo está en buenos términos con las iglesias de Galacia (esto asume que su Carta a los Gálatas fue escrita con anterioridad a 1Corintios, como pienso que es probablemente el caso)" ${ }^{1}$. Según Fitzmyer, su relación con 1Co y 2Co es problemática, "pero probablemente también las precede" ${ }^{2}$, y la fecha entre 54-55. Con menos precisión, Elsa Tamez propone entre 50 y $56^{53}$, pero ciertamente [Galatas] es anterior a Romanos, la última carta.

Para Betz, las semejanzas con 2Co 10-13 no prueban orden secuencial (y es razonable la fecha de 50-55) $)^{54}$. Vielhauer señala: "Aproximadamente al mismo tiempo que $1 \mathrm{Co}^{\prime \prime 5}$. Para Sánchez la fecha es entre 53 y 5756; Vidal la ubica en verano de $52^{57}$, y Betz, entre 52 y 5488; Schierse propone 52-5359; Murphy-O'Connor señala la primavera del 5360; Wickenhauser y Schmid la ubican entre 54 y $58^{61}$; Kümmel, en

${ }^{45}$ Cerfaux, "La Epístola a los Gálatas", 379-380.

${ }^{46}$ Guthrie, New Testament Introduction, 343.

${ }^{47}$ Martyn, Galatians. A New Translation with Introduction and Commentary, 20. En varias partes de la Carta, afirma este autor, se verá la importancia del orden cronológico, particularmente la comprensión de Israel.

${ }^{48}$ Lüdemann, Paulus, der Heidenapostel. Bd. 1. Studien zur Chronologie, 273.

${ }^{49}$ Perrot, "La vie et l'oeuvre de Saint Paul”, 28.

${ }^{50}$ De Boer, Galatians. A Commentary, 7-11.

${ }^{51}$ Martin, New Testament History and Literature, 239.

52 Fitzmyer, “The Letter to the Galatians", 781 (1990); el mismo autor, en "Carta a los Gálatas”, 599 (1968), no había asegurado que fuera anterior.

53 Tamez, "Carta a los Gálatas”, 898; Támez, “Gálatas”, 1509.

${ }^{54}$ Betz, Galatians, 12.

55 Vielhauer, Historia de la literatura cristiana primitiva, 128.

56 Sánchez Bosch, Escritos paulinos, 257. “...la única alternativa realmente interesante sería la de saber si la Carta (Gálatas) es anterior a primera Corintios [...] nos inclinamos en favor de la anterioridad de primera Corintios" (275).

${ }^{57}$ Vidal, Pablo. De Tarso a Roma, 131.

${ }^{58}$ Betz, "Galatians, Epistle to the", 874.

${ }^{59}$ Schierse, Introducción al Nuevo Testamento, 79.

${ }^{60}$ Murphy-O'Connor, Paul. A Critical Life, 184.

${ }^{61}$ Wickenhauser y Schmid, Introducción al Nuevo Testamento, 631. 
54 o $55^{62}$, igual que Brown, quien añade: "Seguramente precede a Romanos" (hacia el 58) ${ }^{63}$. Schnelle apunta a otoño de 5564; Salvador-García habla de 55-56 (i57? ? (65, inmediatamente antes de Romanos y después de las dos cartas a los Corintios.

Al partir de 4,20, Pitta considera que Éfeso es improbable como lugar de redacción de la carta, por lo que piensa en Macedonia o Corinto, aunque fue escrita antes de Romanos (en 55-56) ${ }^{66}$. No obstante, si hubo una segunda visita, la carta es anterior (pero to proteron no implica necesariamente una segunda visita), pues los predicadores fueron "rápidamente" aceptados $(1,6)$. Dunn valora la "segunda" visita $(4,13)$, probablemente después de las cartas a los corintios, pero anterior a Romanos ${ }^{67}$. Vouga cree que, dado el parentesco con 2Corintios y Romanos, según se ponga el acento en una u otra, Gálatas puede haber sido escrita desde Éfeso, Macedonia o incluso Corinto (en 55-57) ${ }^{68}$. Por su semejanza con 2Corintios B (10-13), Mussner propone la fecha de principios del 5769. Para Legasse, la semejanza con 2Co 10-13 (autobiografía, abandono del "Evangelio", cronología y expresiones) indica una misma fecha ${ }^{70}$.

La fecha de la Carta a los Gálatas también es ubicada entre el 49 y el 57, aunque con mucha más variedad e imprecisión que la primera de Corintios, hasta el punto de que, para algunos, Gálatas es la primera, y para otros, la última de las cartas de Pablo. La variación, en este caso, no viene dada por considerar el conjunto de las cartas en torno de un periodo anterior o posterior, sino por su ubicación entre las cartas paulinas, sin que sea fácil precisar al respecto.

\section{El aporte de algunos temas}

Como se ha visto, algunos temas de alguna de las dos cartas tienen relación con otras y ello, quizás, pueda contribuir a fecharlas con más precisión; pero hay otros elementos en los que no parece haber más diferencias que las propias de la comunidad a la que son dirigidas.

\footnotetext{
${ }^{62}$ Kümmel, Introduction to the New Testament, 304.

${ }^{63}$ Brown, An Introduction to the New Testament, 468.

${ }^{64}$ Schnelle, Apostle Paul. His Life and Theology, 271; Schnelle, Einleitung in das Neue Testament, 114.

(Para este autor, la Carta a los Gálatas es posterior a las cartas a los corintios).

${ }^{65}$ Salvador-García, "Carta a los Gálatas", 505.

${ }^{66}$ Pitta, Lettera ai Galati, 34.

${ }^{67}$ Dunn, The Epistle to the Galatians, 8.

${ }^{68}$ Vouga, "La Carta a los Gálatas", 223.

${ }^{69}$ Mussner, Der Galaterbrief, 11.

${ }^{70}$ Légasse, Pablo Apóstol. Ensayo de biografía crítica, 207-208.
} 


\section{Colecta}

Un elemento habitualmente valorado al establecer una cronología de las cartas paulinas es la organización de la colecta. Como es sabido, de la misma se habla en detalle en 2Co 8-9, se hace referencia en Rm 15,25-32, y se alude en 1Co 16,1-4; en cambio, nada se dice de ella en Filipenses ni en Gálatas, aunque en esta última se afirma que en la asamblea de Jerusalén le pidieron que recordara (mnêmoneúômen) a los pobres y Pablo acota que "empeñosamente" (espoúdasa) ha hecho eso $(2,10)$.

Sin embargo, la preocupación por los pobres (de Jerusalén) no necesariamente ha de haber sido ejecutada en forma de colecta. Es probable que Pablo, como lo hizo en otras ocasiones con otros temas, dejara que cada comunidad viera el mejor modo de hacerlo y -lo dice expresamente- Macedonia y Acaya (no lo dice de Galacia) lo organizaron en el modo de una colecta (véase 2Co 8,4; 9,2; Rm 15,26). Es posible, además, que la colecta haya pasado por diversas etapas, dificultades, fracasos y realizaciones, por lo que es difícil concluir la cronología de Gálatas a partir de la ausencia del tema ${ }^{71}$. Lo mismo ha de decirse de Filipenses, en la que el tema quizás está ausente debido a la estructuración, y quizás a la fragmentación de la carta ${ }^{72}$.

\section{Escatología}

La escatología relacionada con la "parusía" que puede verse en 1Corintios no es demasiado diferente a 1Tesalonicenses. Es posible que en Corinto algunos ya se crean resucitados $^{73}$ por un entusiasmo espiritualista. El acento, en Corintios, está en la metamorfosis, que en 1 Tesalonicenses no aparece. En ambas cartas Pablo espera estar vivo cuando venga el Seńor (1Ts 4,15.17; 1Co 15,51-52), algo que probablemente relativizará a partir de las amenazas de muerte que padece, por ejemplo, en Éfeso (2Co 1,8-10; véase Flp 1,23-25; 2,17).

\footnotetext{
${ }^{71}$ Georgi-en Remembering the Poor. The History of Paul's Collection for Jerusalem-propone diferentes etapas y fracasos en la organización de la colecta. En la misma obra (117-120) la presenta como "provocativa"; los sectores conservadores del judeo-cristianismo de Jerusalén han de haber considerado chocante reconocer a los no-circuncidados como "hermanos" (motivo por el que Pablo considera posible que la colecta no fuera aceptada: Rm 15,31). Este sería un motivo más -si fuera el caso- para que Pablo no incorporara el tema en esta carta.

72 Quienes aceptan la colecta como criterio casi universal para la datación de las cartas de Pablo consideran Gálatas y Filipenses como anteriores a las cartas a los Corintios. Otros -como se dijo-, al considerar Filipenses escrita desde Roma, entienden que el tema de la colecta está ausente porque es "asunto terminado".

${ }^{73}$ Barbaglio, La teología de San Pablo, 117.
} 
Nada de esto puede vislumbrarse en Gálatas. La escatología de esta carta tiene estrecha relación con la donación del espíritu (3,2.3.5.14; 4,6.29; 5,16.17.18.22.25; $6,8)^{74}$, la novedad $(4,4)$, la Jerusalén de arriba $(4,26)$, la nueva creación $(6,15)^{75}$ y el nuevo eón $(1,4.5)$, y no con circunstancias históricas concretas de Pablo o de la comunidad. La expectativa en la venida inminente de Jesús nos permite notar la antigüedad de 1Corintios (donde el tema en cuestión es la fe o no en la resurrección de los muertos) ${ }^{76}$, pero no comparar con Gálatas.

\section{Temáticas teológicas}

La semejanza entre Gálatas y Romanos (esta, muy probablemente posterior a 1Corintios, como -por ejemplo- el tema de la colecta lo manifiesta) puede exteriorizar cierta cercanía teológica como particularmente la cristología lo revela y diremos más adelante; pero, por otro lado, en Romanos encontramos, como en 1Corintios, la referencia a la Iglesia "cuerpo"; aunque la metáfora de 1Co 12 ("como" un cuerpo, 12,12) no es análoga a la referencia en Rm 12,5: "Somos un cuerpo en Cristo" y todos "mutuamente miembros".

Sin duda alguna, el contexto de la situación de cada comunidad es decisivo en la redacción de cada carta. Así, 1Corintios insiste más en la comunidad reunida y en temas intracomunitarios (la asamblea, la eucaristía: 14,23-26; 11,17-34; 10,14-22, e incluso la relación entre Pablo y la comunidad, por ejemplo, el tema del trabajo: c. 9; 4,12), mientras que en Gálatas el centro es la novedad de Cristo (la justificación, la fe, el espíritu).

Los problemas que Pablo debe enfrentar en cada caso son decisivos en este sentido y, en general, propios de cada comunidad ${ }^{77}$. Es interesante, por ejemplo, la referencia en ambas cartas sobre el tema del bautismo, pero mientras que en 1 Corintios $(1,13$; 12,13) el acento es comunitario, eclesiológico, en Gálatas (3,27) es más cristológico.

\footnotetext{
${ }^{74}$ Sobre el Espíritu en la primera Corintios y en Gálatas, véase a de la Serna, "La presencia del espíritu en los escritos de San Pablo", 157-180.

${ }^{75}$ La nueva creación (solo en la segunda Corintios y Gáltas) "resulta característica su formulación en presente, así como su concentración antropológica. El que ha recibido el bautismo es ya nueva creación. Parece correcto suponer que la expresión tiene que ver con el bautismo" (Gnilka, Teología del Nuevo Testamento, 989).

${ }^{76}$ Es interesante notar que el tema de la resurrección, en sus dos acepciones -egeirô y anistêmi- solo se encuentra una vez en Gálatas $(1,1)$ mientras lo encontramos 19 veces en la primera de Corintios.

${ }^{77}$ En este sentido, no podemos coincidir con Sánchez Bosch, Maestro de los pueblos, 531-532 (y cercano a él Pastor-Ramos, Para mí, vivir es Cristo. Teología de San Pablo. Persona, experiencia, pensamiento, anuncio, 472-478) que las comunidades paulinas están “centradas en la eucaristía”. No dudamos que es posible que así haya sido, pero nada se dice, fuera de 1Corintios, en las demás cartas del Apóstol, sobre la eucaristía.
} 
El conflicto con los “judaizantes” relaciona Gálatas con 2Corintios y Filipenses, pero el tema parece haber acompañado conflictivamente a Pablo un buen trecho de su ministerio.

Aquí se ubica una cuestión importante que podemos formular de la siguiente manera: ¿Es posible que Pablo, antes de la crisis encontrada en Galacia jamás haya pensado el tema de la justificación por la fe sin las obras de la ley? ¿O el caso de Galacia apenas favoreció la explicación de un dato ligado desde los orígenes de su adhesión a Cristo? Constatamos que la respuesta a esta cuestión suscitó una enorme producción bibliográfica que opone entre sí, de un lado, a los defensores de lo que se denomina new perspective sobre Pablo y el paulinismo y, por otro, sus oponentes que se refieren a una interpretación de Pablo más tradicional y más "luterana". ${ }^{78}$

Hay temas importantes, en este sentido, que encontramos tanto en 1Corintios como en Gálatas: la centralidad de la cruz, por ejemplo: "cruz" en 1 Co $1,17.18$ y en Ga 5,11; 6,12.14, y "crucificado" en 1Co 1,13.23; 2,2.8 y Ga 3,1; 5,24; 6,14; o la no importancia de la circuncisión: 1Co 7,19; Ga 5,6; 6,15.

\section{¿Gnosticismo?}

Se ha hablado de elementos gnósticos (o gnostizantes), lo cual podría ayudar a datar la carta o las cartas de modo más tardío, pero -más allá de lo difícil que es coincidir en esto- tales elementos se han propuesto para ambas cartas ${ }^{79}$.

\section{Aportes}

Como se advierte en las propuestas arriba presentadas, un tema que puede influir en la variación de fechas señaladas es el criterio de unidad de 1Corintios. Vimos, por ejemplo, que Senft y Vidal -entre muchos otros- presentaban en 1Corintios más de una carta. Hemos propuesto, en otra ocasión, que la carta ha de ser una obra única, aunque quizás haya sido reformulada ante el agravamiento de la situación, de la que Pablo se informó oralmente ("los de Cloe"); pero también que entre la primera y la segunda redacción no ha de haber pasado demasiado tiempo, ya que Pablo no llegó a enviarla cuando vio la necesidad o conveniencia de agregar unidades ${ }^{80}$.

\footnotetext{
${ }^{78}$ Penna, "São Paulo, pastor e pensador: una teologia implantada na vida", 409 [Traducción nuestra].

${ }^{79}$ Sobre el gnosticismo en Gálatas, véase a Marxen, Introducción al nuevo Testamento. Una iniciación a sus problemas, 65; y a Vielhauer, Historia de la literatura cristiana primitiva, 138; y en 1Corintios, véase a Fee, The First Epistle to the Corinthians, 11. Especialmente es un tema recurrente en la obra de W. Schmithals.

${ }^{80}$ De la Serna, "los orígenes de 1Corintios" 215.
} 


\section{Historicidad de Hechos de los Apóstoles}

Un aspecto muy importante a la hora de fechar la cronología paulina y, en ella, su correspondencia, radica en el conocimiento de las fuentes.

Es sabido que solo tenemos dos medios para acceder a la persona de Pablo y su obra: sus cartas y el libro de los Hechos de los Apóstoles. Sin embargo, no es unánime entre los estudiosos el criterio acerca de en qué medida y cuánto hemos de valorar históricamente o no el "segundo tomo de Lucas". Las biografías de Pablo, por ejemplo, varían según se valore más o menos esta obra ${ }^{81}$. En nuestro caso, tenemos serias dudas respecto de la valorización histórica de los Hechos. Por ejemplo, Lucas sabe que Cirino realizó un censo, y ubica en ese contexto el nacimiento de Jesús $(2,2)$ : y aunque históricamente sea cierto el hecho, pocos autores ubican hoy el nacimiento de Jesús en este momento.

¿Por qué, entonces, se han de valorar acontecimientos reales como históricamente fiables, por ejemplo, el periodo de Galión, en Corinto (Hch 18,12)? Además, del mismo modo que, para una comprensión del "Jesús histórico", parece que solo deberíamos valorar el Evangelio cuando podemos establecer una serie de criterios bastante objetivos (fuentes múltiples, discontinuidad, etc.), ¿por qué hemos de aceptar acríticamente el libro de Hechos para el conocimiento de la "Iglesia histórica"?

Es evidente que ambas obras tienen una profunda intencionalidad teológica, que el autor quiere presentar tanto en Jesús como en los apóstoles una serie de elementos teológicos (profetas, llenos del espíritu, evangelizadores) ${ }^{82}$. Varios viajes de Pablo a Jerusalén y la presencia de "presbíteros", parecen elaboración lucana de la "historia". ¿Por qué hemos de aceptar "tres viajes" misioneros de Pablo?

Hay momentos en que un hecho narrado parece, en realidad, reflejar más de uno (asamblea de discípulos e intervención de Santiago, visita a Corinto), mientras que sobre algo tan importante como la colecta nada se nos dice en Hechos. Hay elementos narrados en Hechos que permiten, al menos, ser puestos en duda: la intención

\footnotetext{
${ }^{81}$ Es interesante, por ejemplo, la diferencia que se puede notar entre las -por otro lado, excelentes- obras de Rinaldo Fabris, Paolo. L'apostolo delle genti (1997) y de Joaquin Gnilka, Paulus von Tarsus. Apostel und Zeuge (1996), cuya versión italiana hemos consultado (Paolo di Tarso. Apostolo e testimone, 1998). Gnilka, como muchos otros autores alemanes, reconoce una validez secundaria al libro de Hechos, mientras que Fabris valora notablemente la obra lucana. Valga el comentario del mismo Fabris en la rassegne "Alcuni recenti 'biografie' di Paolo", 453-461, en la que analiza las obras de J. Becker, M. F. Baslez, S. Légasse, J. Gnilka y J. Murphy-O’Connor, y finaliza señalando: “Un elemento común a estas cinco biografías paulinas es la preferencia dada al epistolario respecto de los Hechos de los Apóstoles como fuentes para reconstruir la figura y la actividad de Pablo", y finaliza relativizando estas opciones al decir que tanto Hechos como Pablo son "tendenciosos" y que "ninguna fuente histórica es neutral".
}

${ }^{82}$ Johnson, Prophetic Jesus, prophetic Church. The Challenge of Luke-Acts to Contemporary Christians. 
expresa de Lucas de mostrar la pasión de Jesús y la pasión de Pablo en paralelo permite dudar de su historicidad precisa ${ }^{83}$. ¿Era Pablo ciudadano romano? Personalmente, lo ponemos en duda -siguiendo a David Álvarez-, y si lo negamos, ¿̨hubo prisión en Cesarea y en Roma? ${ }^{34}$

No parece sensato, entonces, aceptar acríticamente los datos de Hechos sin someterlos a una lectura mesurada y además reconocer que, en muchísimos casos, no tenemos elementos suficientes para hacerlo. Solo el contraste con los escritos paulinos lo permite y es razonable reconocerlos cuando podamos encontrar elementos convergentes.

En este texto [Hechos], hay sobre todo dudas especialmente en lo que respecta a los viajes misioneros de Pablo, sus relaciones con la comunidad cristiana de Jerusalén, con los judíos y las autoridades romanas. Por importante que sea, este texto debe ser tratado con prudencia, ya que Lucas no nos ofrece una biografía de Pablo a la que suscribir sin reserva. Como todo autor, tiene un proyecto teológico: quiere mostrar la expansión fulgurante del cristianismo en el Imperio romano. Pero a veces no duda en forzar la realidad para un mejor servicio de sus intereses. ${ }^{85}$

Sin embargo, entre el Pablo de Hechos y el de la Carta a los Corintios hemos de señalar coincidencias o compatibilidades. Muchos personajes, por ejemplo, los encontramos en Hechos solo en relación con Corinto y Éfeso, cosa que también ocurre solo en la Carta a los Corintios (Áquila y Prisc[il]a, Apolo, Crispo por caso) ${ }^{86}$.

\section{Datos que aportan las cartas}

En 1Corintios Pablo nos dice que está en Éfeso o cerca $(16,8)$, pero en la Carta a los Gálatas no hay elementos que nos permitan localizarlo, lo cual dificulta la cronología de esta última. Que Pablo no vaya a las comunidades gálatas a enfrentar el problema suscitado, por otra parte, no implica necesariamente que estuviera preso (aunque eso pudiera ocurrir; pero no dice nada al respecto y sería estratégicamente razonable que lo dijera en su apología), y hay diferentes razones que podemos suponer o imaginar (y desconocer) para comprender la ausencia de Pablo en la comunidad ante la crisis.

\footnotetext{
${ }^{83}$ Sobre esto hemos escrito en: De la Serna, Hechos de los Apóstoles. El relato. El ambiente. Las enseñanzas, 57; véase a Gil Arbiol, Pablo en el naciente cristianismo, 239.

${ }^{84}$ Álvarez Cineira, "Pablo ¿̨un ciudadano romano?”; Álvarez Cineira, Pablo y el Imperio romano, 40-44.

${ }^{85}$ Debergé, Je sais en qui j’ai mis ma foi, 13. [Traducción nuestra]; véase a Donfried, "1Tessalonicenses e a cronología paulina", 131-132.

${ }^{86}$ Keener, "Paul and the Corinthian Belivers", 47.
} 


\section{Terminologías}

Hay terminologías que parecen aludir a momentos específicos de las comunidades, pero tanto en Gálatas como en Corintios nos encontramos con comunidades "complicadas".

De los primeros se dice que han abandonado "pronto" el Evangelio (Ga 1,6; las restantes ocasiones en que encontramos el adverbio tajéôs, en Pablo, alude a una deseada "pronta" visita: 1Co 4,19; Flp 2,19.24).

En 4,13, Pablo afirma que la "primera" visita a las comunidades gálatas ocurrió en el marco de una enfermedad. "Proteros", sin embargo, no implica necesariamente una "segunda" visita (que puede haber ocurrido, pero no está necesariamente implicada en el término que también puede traducirse por "anteriormente").

Ambos textos han sido tenidos en cuenta para intentar fechar la carta. Si "pronto" abandonaron el Evangelio y Pablo -se supone- no demoró en enfrentarse al problema (aunque no viajó para hacerlo; entonces ¿por qué viajó?), sin duda deberá tenerse en cuenta una fecha diferente, según se trate de la provincia de Galacia (sur) o la región gálata (norte), donde Pablo evangelizó en diferentes momentos de sus travesías. Sin embargo, "pronto" no necesariamente ha de entenderse como inmediatez cronológica: en 1Co 4,19, Pablo afirma que desea visitar "pronto" la comunidad, pero no alude a un viaje inminente; algo semejante se puede entender en Filipenses, donde Pablo espera poder enviar "pronto" a Timoteo, o incluso ir él mismo, pero tampoco alude a algo inminente.

Es razonable entender la idea del abandono "tan pronto" de un modo retórico ${ }^{87}$ o quizás en el sentido de "tan fácilmente" (está en tiempo presente, ¡no en aoristo!) ${ }^{88}$, o "tan rápidamente" desde la llegada de los predicadores, no desde la partida de Pablo ${ }^{89}$. Como señala correctamente Dunn, "mientras el sentido del texto, por supuesto, ha de haber sido claro para los lectores, permanece ambiguo para nosotros" ${ }^{\prime 0}$. Próteros (véase $B D F \$ 62$ ) puede indicar "primero" (suponiendo una posterior visita) o también "precedente", antes de ahora (en 2Co 1,15 Pablo dice que quería ir "próteros" a la ciudad, y ciertamente no se refiere a la primera visita, por lo que puede traducirse "anteriormente").

Ambos términos podrían aportar criterios para fechar la carta, pero su ambigüedad no nos permite una mínima seguridad o certeza para afirmarlo.

${ }^{87}$ De Boer, Galatians. A Commentary, 39.

${ }^{88}$ Dunn, The Epistle to the Galatians, 40.

${ }^{89}$ Véase a Martyn, Galatians. A New Translation with Introduction and Commentary, 107 (aunque Martyn opta por "pronto" luego de la partida de Pablo).

${ }^{90}$ Ibíd., 40. 
En cambio, sobre la comunidad corintia algunos estudiosos han hablado de "charlatans" (Fee), ,19 "inmadurez persistente" (Barbaglio) ${ }^{92} \mathrm{o}$ "adolescentes" (Martin) ${ }^{93}$. La inmadurez de la comunidad corintia no permite establecer parámetros o imaginar diferentes avances y retrocesos de la predicación paulina que nos permitan fechar algunos elementos por su teología y desarrollo.

\section{Límites para la comprensión}

En ambos casos descubrimos comunidades "en gestación” en los primeros momentos del ministerio paulino; pero también pueden implicar comunidades que, por sus circunstancias o idiosincrasias, retrocedieron respecto del Evangelio predicado por Pablo a momentos anteriores ("no pude hablarles como a espirituales sino como a carnales, como a niños (nêpios) en Cristo" (1Co 3,1), "cuando eramos niños (nêpios) éramos esclavos de los elementos del mundo [...] ¡cómo vuelven otra vez a los débiles y pobres elementos?" (Ga 4,3.9).

Algunos elementos, que merecen ser tenidos en cuenta por las diferencias, no aportan necesariamente elementos contundentes para afirmar o reconocer la precedencia de una carta sobre la otra. El tema de la resurrección, por ejemplo (véase Nota 76), merece una comparación ${ }^{94}$; más aún lo merecen las ideas de "libertad", ya que son destacadas en ambas cartas, con diferentes matices y temáticas.

En ambas, por ejemplo, la libertad contrasta con la esclavitud (1Co 7,21.22; 12,13; Ga 3,28; 4,30.31) y en ambas se destaca lo positivo de "hacerse esclavo" por los demás (1Co 9,19; Ga 5,13), pero en 1Corintios se utiliza con frecuencia "exousía" (x 14, libertad como "posibilidad", como "libertad interna"), mientras que el término está ausente en Gálatas. En cambio, Gálatas destaca la importancia de ser libres, para lo que hemos sido liberados $(4,22.23 .26 ; 5,1.13)$ en una libertad que tenemos por Cristo $(2,4)$, libres de los dioses y elementos $(4,8.9)$, a diferencia de la búsqueda espiritualista de libertad de 1 Corintios (véase 8,$9 ; 10,29$ ).

\footnotetext{
${ }^{91}$ Fee, The First Epistle to the Corinthians, 3.

${ }_{92}$ Barbaglio, La prima Lettera ai Corinzi. Introduzione, versione e commento, 25.

${ }^{93}$ Martin, New Testament History and Literature, 217.

${ }^{44}$ Algo semejante sobre la justicia y la fe destaca Penna, "São Paulo, pastor e pensador: una teologia implantada na vida", 406-410.
} 


\section{Ligeros indicios en favor de la prioridad de 1 Corintios}

En suma, al mirar al interior de ambas cartas, no encontramos elementos decisivos que nos permitan concluir la precedencia de una sobre la otra. Sin embargo, nos parece que hay ligeros indicios que nos permiten suponer que la Carta a los Gálatas es posterior a 1Corintios:

En el capítulo conclusivo de 1Corintios, Pablo nos informa que ha "ordenado" a los Gálatas la colecta (1Co 16,1; el verbo tiatássô en Pablo solo se encuentra en 1Corintios x 4 y en Ga 3,19), algo que es indicio de que la crisis aún no se ha desatado. Es importante tener en cuenta que no todo contacto entre Pablo y una comunidad ha de ser "escrito" necesariamente. Ciertamente, en ocasiones lo es (véase 1Co 5,9; 7,1), pero en otras no parece necesario que así lo sea $(2 \mathrm{Co} 8,4)$. La información oral, como la proporcionada por "los de Cloe" o por "enviados", como Timoteo o Tito (1Ts 3,6; 2Co 7,7), no puede dejar de tenerse en cuenta. 1Co 16,1 no implica necesariamente una carta perdida; por tanto, tampoco debemos suponer irremediablemente esta $\mathrm{u}$ otra correspondencia en diferentes momentos.

Son, además, de destacar los paralelos notables entre Gálatas y Romanos (ver tabla).

Tabla 1. Paralelos entre Gálatas y Romanos

\begin{tabular}{|l|l|l|}
\hline GÁLATAS & ROMANOS & \\
\hline $1,15-16$ & $1,1-5$ & Separado como apóstol \\
\hline $2,15-21$ & $3,19-28$ & Justicia por la fe \\
\hline $3,6-25.29$ & $4,1-25$ & Abraham \\
\hline $3,26-28$ & $6,3-5$ & Bautismo \\
\hline $4,1-7$ & $8,12-17$ & Esclavitud y libertad \\
\hline $4,21-31$ & $9,6-13$ & Ley y promesa \\
\hline $5,13-15$ & $13,8-10$ & Libres por el amor \\
\hline 5,17 & $7,13-15$ & Contraste entre querer y obrar \\
\hline $5,16-26$ & $8,12-27$ & Vida en el Espíritu \\
\hline
\end{tabular}

Fuente: Elaboración a partir de U. Schnelle, Apostle Paul. His Life and Theology (Grand Rapids, MI: Baker Academic, 2005), 270; U. Schnelle, Einleitung in das Neue Testament (Basel-Wien-München: Vandenhoeck \& Ruprecht, 2005), 113; y Boring, Introduzione al Nuovo Testamento I (Brescia: Paideia, 2016), 436.

Esto permite a Boring preguntarse si el tema de la justificación está en el pensamiento paulino desde los comienzos (datación antigua de Gálatas), o si, por ser cartas de ocasión, la crisis (datación tardía) provocada por los misioneros rivales lleva 
a que esta se presente por primera vez en Galacia, para luego desarrollarse de modo más meditado en Romanos.

Ninguno de los argumentos es decisivo (concluye, pero) el peso de la documentación induce a pensar que la Carta a los Gálatas fue escrita en un momento relativamente reciente de la misión de Pablo en el Egeo, más o menos en el mismo periodo de 2Co 10-13 y poco antes de la Carta a los Romanos.95

Finalmente señalemos que, tras una detallada comparación de los textos, Gregory Tatum propone el siguiente orden: (a) 1Co; (b) 2Co 10-13; (c) Ga; (d) Flp; (e) 2Co 1-9; (f) $\mathrm{Rm}^{96}$.

La necesidad que ve Pablo de defenderse apologéticamente la encontramos en Ga 1-2, Flp 3 y 2Co 11; la introducción de "otro evangelio" lo descubrimos en Ga 1 y 2Co 10-13, como se ha señalado. Parece sensato tener en cuenta estos paralelos que Tatum destaca.

\section{Conclusión}

$\mathrm{Al}$ volver al ejemplo inaugural, nos parece probable que, en 1Co 12, Pablo cita el texto bautismal que él conoce y que refiere a judíos y griegos, esclavos y libres; pero en la comunidad Pablo destaca y alienta el lugar de la mujer en la participación en las asambleas (1Co 7; 11,2-16). Cuando (poco) tiempo después escribe a los gálatas y retoma el texto bautismal en un nuevo contexto, inspirado en 1Co 7 y 11, Pablo añade el par "varón y mujer" para señalar que todos los que se creen más cercanos a Dios y -por tanto- bendecidos, no lo son más que aquellas y aquellos que son tenidos por excluidos.

Ya no se agradece por haber nacido judío, libre y varón, sino que los paganos, los esclavos y las mujeres son tan reconocidos como los demás. "Ya no hay" nada de lo que separa, porque la fraternidad y sororidad incluye a todas y todos en Cristo, y Pablo lo expresa con claridad incluyendo al "hombre", que es "varón y mujer" en el discipulado de iguales "de Cristo".

\section{Referencias}

Álvarez Cineira, David. “Pablo ¿un ciudadano romano?”. Estudio agustiniano 33 (1998): 455-486. . Pablo y el Imperio romano. Salamanca: Sígueme, 2009.

\footnotetext{
${ }^{95}$ Penna, "São Paulo, pastor e pensador: una teologia implantada na vida”, 436-437. [Traducción nuestra].

${ }^{96}$ Tatum, New Chapters in the Life of Paul. The Relative Chronology of his Career, 126-130.
} 
Barbaglio, Giuseppe. La prima Lettera ai Corinzi. Introduzione, versione e commento. Bologna: Edizioni Dehoniane Bologna, 1996.

. La teología de San Pablo. Salamanca: Secretariado Trinitario, 2006.

Barrett, Charles Kingsley. La prima Lettera ai Corinti. Testo e commento. Bologna: Edizioni Dehoniane Bologna, 1979.

Betz Hans Dieter. Galatians. Philadelphia (PA): Fortress Press, 1987.

. "Galatians, Epistle to the". En The Anchor Bible Dictionary II, editado por D. N. Freedman, 872-875. New York-London-Toronto-Sydney-Auckland: Doubleday, 1992.

Betz, H. D., y M. M. Mitchell. “Corinthians, First Epistle to the”. En The Anchor Bible Dictionary I, editado por D. N. Freedman, 1139-1148. New York-LondonToronto-Sydney-Auckland: Doubleday, 1992.

Boring, M. Eugene. Introduzione al Nuovo Testamento I. Brescia: Paideia, 2016.

Brown, Raymond E. An Introduction to the New Testament. New York (NY): Doubleday, 1997.

Cambier, J. "La primera Epístola a los Corintios”. En Introducción a la Biblia, dirigido por A. Robert y A. Feuillet, II, 389-405. Barcelona: Herder, 1965.

Carrez, Maurice. "Paul et l'église de Corinthe". En Introduction à la Bible. Édition nouvelle. Tomo III. Le Nouveau Testament. Vol. 3. Les lettres apostoliques, dirigido por A. George y P. Grelot, 51-93. Paris: Desclée, 1977.

Cerfaux, Lucien. "La Epístola a los Gálatas”. En Introducción a la Biblia, dirigido por A. Robert y A. Feuillet, II, 378-388. Barcelona: Herder, 1965.

Collins, Raymond F. First Corinthians. Editado por Daniel Harrington. Collegeville (MN): A Michael Glazier Book. The Liturgical Press, 1999.

Conzelmann, Hans. First Corinthians: A Commentary on the First Epistle to the Corinthians. Philadelphia (PA): Fortress Press, 1975.

De Boer, Martinus C. Galatians. A Commentary. Louisville (KY): Westminster John Knox Press, 2011.

De la Serna, Eduardo. "El lugar de la mujer en los escritos de Pablo". En "Dónde está el espiritu está la libertad”. Homenaje a Luis Heriberto Rivas con motivo de sus 70 años, coordinado por J. L. D’Amico y E. de la Serna, 379-407. Buenos Aires: San Benito, 2003. 
. Hechos de los Apóstoles. El relato. El ambiente. Las enseñanzas. Buenos Aires: Claretiana, 2004.

. "La presencia del espíritu en los escritos de San Pablo", Revista bíblica 77-78. Homenaje a Armando Levoratti (2015-2016): 157-180.

. "Los orígenes de 1Corintios". Revista bíblica 72 (1991): 192-216.

Debergé, Pierre. Je sais en qui j’ai mis ma foi. Paris: Artège Éditions, 2013.

Donfried, Karl P. “1Tessalonicenses e a cronología paulina”. En Paulo. Uma teologia em construção, organizado por A. Dettwiler, J. D. Kaestli y D. Marguerat, 115-144. São Paulo: Loyola, 2011.

Dunn, James D. G. The Epistle to the Galatians. Grand Rapids (MI): Baker Academic, 1993.

Eisenbaum, Pamela. Pablo no fue cristiano. El mensaje original de un apóstol mal entendido. Estella (Navarra): Verbo Divino, 2014.

Fabris, Rinaldo. Paolo. L'apostolo delle genti. Milano: Paoline, 1997. . "Alcuni recenti 'biografie’ di Paolo". Rivista bíblica 52 (2004): 453-461.

Fee, Gordon D. The First Epistle to the Corinthians. Grand Rapids (MI): Eerdmans, 1991.

Fitzmyer, Joseph A. “Carta a los Gálatas”. En Comentario bíblico San Jerónimo. Tomo III: Nuevo Testamento 1, dirigido por R. E. Brown; J. A. Fitzmyer; y R. E. Murphy, 597-622. Madrid: Cristiandad, 1972.

. First Corinthians. A New Translation with Introduction and Commentary. New Haven-London: Yale University Press, 2008.

. "The Letter to the Galatians". En The New Jerome Biblical Commentary, editado por R. E. Brown; J. A. Fitzmyer; y R. E. Murphy, 780-790. Upper Saddle River (NJ): Prentice Hall, 1990.

Foulkes, Irene. "Primera Carta a los Corintios". En Comentario biblico latinoamericano. Nuevo Testamento, dirigido por A. Levoratti, 817-858. Estella (Navarra): Verbo Divino, 2003.

- Problemas pastorales en Corinto. Comentario exegético-pastoral a 1Corintios. San José-Costa Rica: DEI, 1996.

Georgi, Dieter. Remembering the Poor. The History of Paul's Collection for Jerusalem. Nashville (TN): Abingdon Press, 1992. 
Gil Arbiol, Carlos. Pablo en el naciente cristianismo. Estella (Navarra): Verbo Divino, 2015.

Gnilka, Joachim. Paolo di Tarso. Apostolo e testimone. Brescia: Paideia, 1998. . Teología del Nuevo Testamento. Madrid: Trotta, 1998.

Guthrie, Donald. New Testament Introduction. Leicester (IL): Intervarsity Press, 1990.

Hays, Richard B. First Corinthians. [Interpretation. A Bible Commentary for Teaching and Preaching]. Louisville (KY): Westminster John Knox Press, 2011.

Horsley, Richard A. 1Corinthians. Nashville (TN): Abingdon Press, 1998.

Johnson, Luke Thimoty. Prophetic Jesus, prophetic Church. The Challenge of Luke-Acts to Contemporary Christians. Grand Rapids (MI): W. B. Eermans Publishing Co., 2011.

Keener, Craig S. "Paul and the Corinthian Belivers". En The Blackwell Companion to Paul, editado por S. Westerholm, 46-62. Hoboken (NJ): Wiley Blackwell, 2011.

Kugelman, Richard. "Primera Carta a los Corintios". En Comentario biblico San Jerónimo. Tomo IV: Nuevo Testamento, dirigido por R. E. Brown; J. A. Fitzmyer; y R. E. Murphy, 9-62. Madrid: Cristiandad, 1972.

Kümmel, Werner Georg. Introduction to the New Testament. Nashville (TN): Abingdon Press, 1975.

Lambrecht, Jan. "1Corintios". En Comentario bíblico internacional, dirigido por W. R. Farmer, 1459-1488. Estella (Navarra): Verbo Divino, 1999.

Lang, Friedrich. Die Briefe an die Korinther. Göttingen: Vandenhoeck \& Ruprecht in Göttingen, 1986.

Légasse, Simon. Pablo Apóstol. Ensayo de biografía critica. Bilbao: Desclée de Brouwer, 2005.

Lohse, Eduard. Introducción al Nuevo Testamento. Madrid: Cristiandad, 1975.

Lüdemann, Gerd. Paulus, der Heidenapostel. Bd. 1. Studien zur Chronologie. Göttingen: Münchener Digitalesierungs Zentrum, 1980.

Martin, Dale B. New Testament History and Literature. New Haven: Yale University Press, 2012.

Martyn, James Louis. Galatians. A New Translation with Introduction and Commentary. New York (NY): Doubleday, 1997. 
Marxen, Willy. Introducción al nuevo Testamento. Una iniciación a sus problemas. Salamanca: Sígueme, 1983.

Mussner, Franz. Der Galaterbrief. Freiburg-Basel-Wien: Herder, 1981.

Murphy-O’Connor, Jerome. Pablo. Su historia. Madrid: San Pablo, 2008. . Paul. A Critical Life. Oxford (U. K.): Clarendon Press, 1996. . "The First Letter to the Corinthians". En The New Jerome Biblical Commentary, editado por R. E. Brown; J. A. Fitzmyer; y R. E. Murphy, 798-815. Upper Saddle River (NJ): Prentice Hall, 1990.

Orr, Willliam F., y James Arthur Walter (trads.). ICorinthians. [The Anchor Bible Vol. 32]. New York (NY): Doubleday, 1982.

Pastor-Ramos, Federico. Para mí, vivir es Cristo. Teología de San Pablo. Persona, experiencia, pensamiento, anuncio. Estella (Navarra): Verbo Divino, 2010.

Penna, Romano. "São Paulo, pastor e pensador: una teologia implantada na vida". En Paulo. Uma teologia em construção, organizado por A. Dettwiler, J. D. Kaestli y D. Marguerat, 385-412. São Paulo: Loyola, 2011.

Perrot, Charles. "La vie et l'oeuvre de Saint Paul". Introduction à la Bible. Édition nouvelle. Tomo III. Le Nouveau Testament. Vol. 3. Les lettres apostoliques, dirigido por A. George y P. Grelot, 15-38. Paris: Desclée, 1977.

Pitta, Antonio. Lettera ai Galati. Bologna: Edizioni Dehoniane Bologna, 1996.

Salvador-García, Miguel. "Carta a los Gálatas”. En Comentario al Nuevo Testamento, dirigido por S. Guijarro Oporto y M. Salvador-García, 503-520. Estella (Navarra): La Casa de la Biblia, 1995.

. "Primera Carta a los Corintios". En Comentario al Nuevo Testamento, dirigido por S. Guijarro Oporto y M. Salvador-García, 449-480. Estella (Navarra): La Casa de la Biblia, 1995.

Sánchez Bosch, Jordi. Escritos paulinos. Estella (Navarra): Verbo Divino, 1999. - Maestro de los pueblos. Una teología de Pablo, el apóstol. Estella (Navarra): Verbo Divino 2007.

Schierse, Franz Joseph. Introducción al Nuevo Testamento. Barcelona: Herder, 1983.

Schnelle, Udo. Apostle Paul. His Life and Theology. Grand Rapids (MI): Baker Academic, 2005. 
. Einleitung in das Neue Testament. (Edición revisada). Basel-Wien-München: Vandenhoeck \& Ruprecht, 2005.

Schrage, Wolfgang. Der erste Brief an die Korinther I. Zürich-Neukirchener: Benziger, 1991.

Senft, Christophe. La première Épitre de Saint Paul aux Corinthiens. Paris: Delachaux \& Niestle, 1979.

Tamez, Elsa. "Carta a los Gálatas". En Comentario bíblico latinoamericano. Nuevo Testamento, dirigido por A. Levoratti, 895-912. Estella (Navarra): Verbo Divino, 2003.

. "Gálatas". En Comentario biblico internacional, dirigido por W. R. Farmer, 1508-1520. Estella (Navarra): Verbo Divino, 1999.

Tatum, Gregory. New Chapters in the Life of Paul. The Relative Chronology of his Career. Washington D. C.: The Catholic Biblical Association of America, 2006.

Taylor, Mark. 1Corinthians. An Exegetical and Theological Exposition of Holy Scripture. [The New American Commentary Vol. 28]. Nashville (TN): B\&H Publishing Group, 2014.

Thiselton, Anthony C. The First Epistle to the Corinthians. [The New International Greek New Testament Commentary]. Grand Rapids (MI)-Carlisle (U. K.): Wm. B. Eerdmans Publishing Co.-Paternoster Press, 2000.

. The Living Paul. An Introduction to the Apostle's Life and Thought. Downers Grove (IL): InterVarsity Press, 2009.

Vidal, Senén. Pablo. De Tarso a Roma. Santander: Sal Terrae, 2007.

Vielhauer, Philipp. Historia de la literatura cristiana primitiva. Salamanca: Sígueme, 1991.

Vouga, François. "La Carta a los Gálatas". En Introducción al Nuevo Testamento. Su historia, su escritura, su teología, editado por D. Marguerat, 213-228. Bilbao: Desclée de Brouwer, 2008.

. "La primera Carta a los Corintios". En Introducción al Nuevo Testamento. Su historia, su escritura, su teología, editado por D. Marguerat, 179-198. Bilbao: Desclée de Brouwer, 2008. . Yo Pablo. Las confesiones del Apóstol. Santander: Sal Terrae, 2006.

Wickenhauser Alfred, y Josef Schmid, Introducción al Nuevo Testamento. Barcelona: Herder, 1978. 